\title{
CONSUMER COGNITION AND PRICING IN THE NINES IN OLIGOPOLISTIC MARKETS
}

\author{
KAUSHIK BASU \\ Department of Economics \\ Cornell University \\ Ithaca, NY 14853 \\ kb40@cornell.edu
}

The paper fully characterizes the Bertrand equilibria of oligopolistic markets where consumers may ignore the last (i.e., the right-most) digits of prices. Consumers, in this model, do not do this reflexively or out of irrationality, but only when they expect the time cost of acquiring full cognizance of the exact price to exceed the expected loss caused by the slightly erroneous amounts that are likely to be purchased or the slightly higher price that may be paid by virtue of ignoring the information concerning the last digits of prices. It is shown that in this setting there will always exist firms that set prices that end in nine though there may also be some (nonstrict) equilibria where a non-nine price ending occurs. It is shown that all firms earn positive profits even in Bertrand equilibria. The model helps us understand in what kinds of markets we are most likely to encounter pricing in the nines.

\section{INTRODUCTION}

A large body of research has confirmed what shoppers the world over know, namely, that a disproportionately large number of goods are priced to end in a nine. Hamburgers for 99 cents; shoes for $£ 49$; and so on. There is also a substantial literature that analyzes this phenomenon of "pricing in nines", ${ }^{1}$ which is closely related to what is referred to in the marketing literature as the phenomenon of "odd pricing" (e.g., Evans and Berman, 1997, p. 626). Clearly, this kind of pricing is evidence of consumer carelessness in processing the less important (i.e., the rightmost) digits of a price. However, while the standard presumption is that

I am grateful to Talia Bar, Ted O'Donoghue, Hyejin Ku, Omar Robles, and two anonymous referees and a coeditor of this journal for helpful comments.

1. See, for instance, Bader and Weinland (1932), Ginsberg (1936), Schindler and Kibarian (1996), Basu (1997), Schindler and Kirby (1997), Stiving and Weiner (1997), Shy (2000), Stiving (2000), Ruffle and Shtudiner (2003), Anderson and Simester (2003), Friberg and Matha (2003).

(C) 2006, The Author(s)

Journal Compilation (C) 2006 Blackwell Publishing

Journal of Economics $\mathcal{E}$ Management Strategy, Volume 15, Number 1, Spring 2006, 125-141 
the consumer treats the last digits as if they were zero, ${ }^{2}$ it will be assumed here that consumers act rationally and are either fully cognizant of all digits or assume the last digits to be whatever they are, on average, in reality. And which of these two behaviors they choose itself has a meta-rational basis. Interestingly, in this area of consumer choice, metarationality and irrationality look (at least on the face of it) behaviorally similar.

There is a substantial literature that has speculated about the widespread prevalence of nine as the right-most digit in prices. That this actually helps sell larger quantities has also been demonstrated through controlled randomized experiments. Anderson and Simester (2003), for instance, persuaded a national mail-order company that sells women's clothing to send out different versions of a catalog to separate, randomly selected customer samples, where the same products had 9 price endings in some catalogues and non-9 price endings in others. They found that when sold at the higher price that ended in 9 (in one example, selling the same product for $\$ 49$ instead of \$45) this raised demand by as much as $40 \%{ }^{3}$ The question is: why does this happen? A variety of explanations are available. It is, for instance, possible that some mental units are easily "available" or "accessible" to the mind and round numbers are salient among them (Kahneman and Tversky, 1979; Fazio et al., 1982; Thaler, 1985). So when we see a price like $\$ 49$ we immediately perceive this as actually $\$ 50$ (the nearest round number) with a discount (Schindler and Kirby, 1997) and feel tempted to pick up the "bargain."

This perception that a product being sold for a price ending in nines is somehow on sale has been widely noted (see, for example, Anderson and Simester, 2003; Inman et al., 1990). This can be a matter of illusion or irrationality on the part of the consumer. But, and more surprisingly, this can also be a rational response of using a rule of thumb, given that our brain capacity is limited and given that some firms do actually use 9-price-endings for products on sale. J. Crew and Ralph Lauren, for instance, often use 00-cent endings on regularly priced merchandise and 99-cent endings on discounted items (Anderson and Simester, 2003a).

The aim of the present paper is to explain the widespread phenomenon of 9-price ending, while maintaining the assumption of consumer rationality as far as possible. First, I shall assume that when

2. See Gabor and Granger (1964), Wilkie (1990), Schindler and Kibarian (1996), Nagle and Holden (1995).

3. For a mail order company selling lots of goods, raising the price of one good from \$45-49 does not necessarily mean a rise in profit, even though the demand for the product rises. The authors do not investigate this, but it is possible that this increased demand is offset by a decline in demand for other goods in the catalogue. 
consumers decide to use only partial information in making their decisions, for instance, ignoring information about the last digits of a price, they do so because it is rational to do so. The processing of information is costly for the brain and so in certain situations it is rational to economize on the use of information. Second, when we recognize that consumers do often ignore the last digits of a price, we shall not assume that they assume this to be zero.

The tendency to equate "ignoring a digit" with "treating it as zero" is widespread in the literature. Anderson and Simester (2003), for instance, observe that a consumer who looks at a price like $\$ 43$ and ignores the right-most digit, treats this as $\$ 40$. This is a common interpretation in the literature but there seems to be no basis for it. Note that "ignoring the last digit" could be described more explicitly as "not looking at the last digit and presuming it to be $x$." Once we state it in this way it is not at all evident why this $x$ should always be zero. It is much more reasonable to assume that consumers, from their everyday life experience, have an opinion of what the last digit or digits typically look like and so when they ignore looking at the last digit or digits they presume it to be whatever it, typically, is.

What the model illustrates is that assuming this kind of rationality on the part of consumers can generate behavior and price patterns that are similar to what would happen if consumers were prone to certain psychological illusions or even delusions. This is not to deny that consumers, occasionally, do suffer from illusions. ${ }^{4}$ But for the phenomenon being analyzed here there is no need to make such an assumption.

Interestingly, though the 9-price endings can be explained in these competing ways, there are subtle differences that emerge in terms of profits earned by firms and consumer welfare, depending on whether or not we assume consumers to be rational. All this is illustrated in a fairly realistic model with many suppliers and oligopolistic behavior. This paper develops the idea of a "sophisticated Bertrand equilibrium" and characterizes the class of possible equilibria.

Initial steps toward such a full-fledged model were taken in Basu (1997). In that model, like here, consumers replaced the last digits of a price with the average of the last digits that prevailed on the market. But,

4. Indeed, there are certain kinds of evidence that would be hard to explain in terms of purely rational behavior. Consider the evidence, reported above, where a mail order catalogue company found that the same good priced at $\$ 49$ had a higher demand than when it was priced at $\$ 45$. The model built here can explain why demands at $\$ 49$ and $\$ 45$ would be the same. Therefore, the finding of higher demand at $\$ 49$ suggests that there is some additional psychological factor at play here.

There may also be a case for running similar experiments a few more times to check the robustnessness of the empirical finding. 
unlike here, they did so compulsively. It was not a rational decision to ignore the last digits. Moreover, there was no strategic behavior among firms. The exercise was simply one of an optimization problem of a monopolist. Expanding the analysis to fully rational consumer behavior and an oligopolistic markets allows us to address larger questions. And some of the results turn out to be sharply different from what was obtained in Basu (1997). In the case of a monopoly, it was shown that the consumer's tendency to ignore the last digits hurt the monopolist. On the other hand, in this paper, with fully rational consumers and an oligopolistic market structure, firms end up benefiting from the fact that it may be rational for consumers to ignore the last digits of a price. This is true even if firms are Bertrand competitors.

The paper begins by giving a brief intuitive sketch of the main argument. The formal model is developed after that, in Sections 3 to 5. Some of the more speculative discussion is relegated to the last section.

\section{Sketch of the Argument}

Given the limits of the human brain, it is reasonable to assume that human beings will not be fully informed. When a person goes through a supermarket buying goods, is it worthwhile for him to study and take in the price information of each product in full? It is not evident that the answer to this will be yes, contrary to what early textbook models of economics suggested. Indeed, it may not be rational to take in so much information. ${ }^{5}$ If, for instance, she looked only at the dollar part of the prices and took her purchase decisions based on that, she would make a few wrong decisions, true, but the time saved by using this strategy may be well worth that little loss. I shall later model the circumstances where such time saving is worthwhile.

Once consumers begin to behave this way, a Bertrand firm may not find it worthwhile to undercut other firms by a small amount because this may go unnoticed by the consumers. If this happens, then the price cut would not lead to a higher demand and therefore would not be worthwhile. This could result in an equilibrium where, despite Bertrand competition, firms earn positive profits. One implication of this model (or, more accurately, of possible extentions of this model) is that 9-ending prices are less likely to occur in wholesale markets, where the buyer, by

5. Anderson and Simester (2003a) report a study (by P. Dickson and A. Sawyer) in which, as shoppers placed items in carts, researchers asked them the prices of what they had just chosen to buy. Less than half the shoppers gave an accurate price. Buying without full cognizance of price may at first sight seem irrational. But given our brain's limited capacity and the enormous amount of information we are required to process it is not unreasonable (or even irrational) for us to use simple rules of thumb instead of fully informed, detailed decision procedures (see Gigerenzer and Goldstein, 1996; Todd, 2001; Todd and Gigerenzer, 2003). 
virtue of the fact that she makes large purchases, finds it rational to be sensitive to small price changes.

Just as this paper models the consumer's decision concerning how much information to collect, it is in principle possible to analyze how much information firms should collect about consumers. This question, however, is typically ignored in the theoretical literature (for an exception, see Lui and Serfes, 2004) and I do the same here. But it is noteworthy that in this age of information technology it is possible for firms to collect information easily about more and more refined partitions of consumers and to use this for discriminatory pricing.

\section{BASIC CONCEPTS AND NOTATION}

Because formal, quantitative analysis of this problem is relatively new, it is useful to develop some algebra specifically suited to this kind of study.

In this paper, I shall be concerned with prices that treat a cent as an indivisable unit. Hence, a price is always expressed up to two places after the decimal, that is, by numbers like 1.50 or 19.95 . Let $\mathbb{P}$ be the collection of all such nonnegative numbers. For every $p \in \mathbb{P}$ it will at times be useful to write it as $(d, c)$, where $d$ is the "dollar part" of $p$ and $c$ is the "cent part" of $p$. Let $\phi$ be a function, on domain $\mathbb{P}$, such that, for every $p \in \mathbb{P}, \phi(p)=(d, c)$, as defined above. I shall at times write $\phi(p)=$ $(d(p), c(p))$. Hence, $d(12.95)=12$ and $c(12.95)=95$. Let $\psi$ be the inverse of $\phi$. That is, $\psi(\phi(p))=p$, for all $p \in \mathbb{P}$. Therefore, $\psi(12,95)=12.95$.

We shall be concerned, in this paper, with an industry where the aggregate demand function for the good in question is given by

$x=x(p)$,

for all $p \in \mathbb{P}$. And it is assumed that, if $p, p^{\prime} \in \mathbb{P}$ such that $p>p^{\prime}$, then $x(p)<x\left(p^{\prime}\right)$.

This industry has $n$ identical firms. Each firm's per unit cost of production is given by $k \in \mathbb{P}$. For the problem to be nontrivial, I will assume that $x(k+1)>0$. I shall, on occasions, refer to the marginal cost as $(d(k), c(k))$, where $(d(k), c(k))=\phi(k)$.

\section{RATional 'IRRATIONALity' OF the CONSUMER}

While it is true that traditional economic theory was wrong (as the new "behavioral economics" reminds us) in its assumption that consumers are always rational, it is also possible to err on the other side by treating every seemingly irrational behavior as irrational behavior. Consider, for instance, the fact that human beings make so many decisions without seriously weighing the pros and cons of the alternatives. Once we 
recognize that the act of weighing the pros and cons of a decision is itself costly in terms of time and the use of our limited brain capacity, it may make good sense to leave some decisions to gut feeling, reflexive action, or simply picking the default option. These 'irrational' actions may, in other words, be rational at a more fundamental level (Basu, 1988, 1992, Section 12.4).

There is a large literature in psychology that illustrates how human beings often use simple rules of thumb to make decisions, instead of collecting all relevant information and then making decisions; and how these "fast and frugal" rules may in fact turn out to be reasonable (Gigerenzer and Goldstein, 1996; Gigerenzer and Selten, 2001). If, for instance, people were given pairs of cities and asked which of each pair had the higher population and people named the city they were more familiar with, Goldstein and Gigerenzer (1999) showed that they would be right significantly more often than if they chose the answer at random. Given that the collection of information can be costly in terms of time and money, for certain purposes the use of this heuristic may be the rational course. It is this general idea that I shall now use in the context of consumer decisionmaking concerning what to buy.

Consider a consumer in a large grocery store doing her week's shopping. She can stand in front of each competing brand, study the price fully, let that information sink in, and then make a purchase. In this way, her purchase will be just right, given her needs, but she will end up having spent more time in the store than she would if she were prepared to make mistakes. If time is valuable it may be rational for her not to dwell too long on taking in every good's price information. Now, if a person is keen on economizing on the acquisition of information concerning some digits, it obviously makes sense to start with the right-most digits. When we are thinking of small purchases, for instance, in a grocery store, this will typically refer to the cents part of the price. (For larger purchases, for instance, in buying a car it may be the last one or two dollar digits that one ignores-see also note 10.)

Let us formalize this obvious observation as follows. In making a purchase, the consumer can go about it in two ways. First, she could look at only the dollar part of the price and assume that the cent part of the price is whatever is the average cent parts of prices of all goods sold in this market and then decide which shop to buy from (picking randomly from among those that seem to charge the lowest price) and how much to purchase. Let us call this action A. Second, she could take in the price information of all offers fully; and then decide which shop to buy from (again randomizing over shops that charge the lowest price) and how much to buy. I shall call this action B. 
Assume that the latter action entails a (brain capacity or time) cost of $b(>0)$ whereas the former is costless. ${ }^{6}$ In other words, I am assuming that we have a sense of the average of the cent parts of prices of all goods that are offered in the market. This is the kind of information we acquire automatically, and costlessly, in the act of going through life.

In this model we will consider only one good, which is sold by $n$ producers - a typical oligopoly model. In other words, there will be $n$ prices being offered in the market. The producer's (or seller's) behavior will be modeled in the next section. Let me describe a typical consumer's behavior here.

The consumer's utility function is given by $u=u(x, M)$, where $x$ is the amount of the good consumed and $M$ the amount of money left with the consumer after the purchase of the good. If the price of the good at which he purchases the product is $p$ and her income is $y$, then $u=u(x, y-p x)$. This is a semiindirect utility function. Since $y$ will be taken to be fixed throughout, we will suppress it and write the semiindirect utility function as

$v=v(x, p) \equiv u(x, y-p x)$.

Note that the consumers' demand function, described above by (1), is easily derived from this. In particular, $x(p)=m\left[\arg \max _{x} v(x, p)\right.$ ], where $m$ is the number of (identical) consumers.

To describe a consumer's cognition problem, it is convenient to, at times, abuse notation a little and write $\phi(p)$ in place of $p$ in (1) and (2). That is, I shall, on occasion, write the $v(\cdot)$-function as $v(x,(d, c))$ and the demand function as $x(d, c)$, where $(d, c)=\phi(p)$. In other words, $v(x,(d, c))$ and $x(d, c)$ refer to $v(x, \psi(d, c))$ and $x(\psi(d, c))$.

Suppose the prices prevailing in the market are given by $\left\{\left(d_{i}, c_{i}\right)\right\}_{i \in S}$, where $S$ is the set of sellers, with $\# S=n$. Anticipating what will turn out to be true in equilibrium, let me make the harmless assumption that the dollar part of all prices are the same. That is, $d_{i} \equiv d$, for all $i \in S$. Hence, the vector of prices that the consumer confronts may be written as $\left\{\left(d, c_{i}\right)\right\}_{i \in S}$.

Suppose the consumer opts for action B. Then her total utility is given by

$v^{B}=\max _{i \in S} v\left(x\left(d, c_{i}\right),\left(d, c_{i}\right)\right)-b$.

If, on the other hand, she goes for action $A$, then her utility is given by $v^{A}=\underset{i}{E} v\left(x(d, \bar{c}),\left(d, c_{i}\right)\right)$,

where $\bar{c}=\left(c_{1}+\cdots+c_{n}\right) / n$, and $E_{i}$ is the expectations operator.

6. It would be analytically equivalent (though the algebra would get more complicated) if it was assumed that the brain use or time cost of action $B$ was $t$ and the brain use or time cost associated with action $A$ was $t+b$. 
The consumer will choose action $A$ if and only if $v^{A}>v^{B}$.

Hence, a consumer who ignores price information about the cent part of the price incurs two kinds of cost. He may fail to purchase from the seller offering the lowest price and the amount she consumes may be different from what would be optimal for the price that she actually pays.

This model of consumer cognition can be made more sophisticated in many different ways. First note that any decision problem that involves costly evaluation, as in this exercise (recall $b>0$ ), has an infinite regress problem. If making an evaluated choice between two alternatives, $X$ and $Y$, involves a cost, then making an evaluated choice between whether to make an evaluated choice between $X$ and $Y$ or to choose at random between them will, presumably, involve some cost; and so on. ${ }^{7}$ Second, if the consumer knows the distribution of $c^{\prime}$ s on the market but not the $c$ facing her, it is not typically the case that she will use the average value of $c$ to decide how much to buy. And even if she did not know the distribution of $c^{\prime}$ s but merely knew the value of the expectation of the $c^{\prime} s$, it is not obvious that she should use exactly the expectation to decide how much of the good to consume. The above model, in these kinds of cases, is best thought of as a reasonable approximation of precisely rational behavior. Morever, the main results of this paper (this will be obvious later) will not hinge on these refinements. The result will be invariant to many different formulations of consumer decisionmaking under limited brain capacity.

Fortunately, we do not need to model the full range of consumer behavior, when decisionmaking is costly. For the purpose of the present paper it is enough to assume that if the cent parts of all prices prevailing in the market are the same, then $E v^{A}>E v^{B}$, that is, the consumer will choose action $A$. The rationale behind this assumption is not hard to see. If the cent part of every price on the market is $\bar{c}$, then it is not unreasonable to assume that the consumer knows (from everyday life) that the cent part of a randomly selected good will almost certainly be $\bar{c}$. Hence $E v^{A} \simeq E v^{B}+b$. For a person placing a large order (for example, agreeing to a long-distance phone price for the next 2 years, or buying on the wholesale market) this may not be a realistic assumption since the possibility (even if imagined) of a small error may make the person take full cognizance of the price. But for everyday retail shopping it seems fine; and in the present paper I shall make use of this assumption.

7. A formal expression of this infinite regress problem and the demonstration of its essential unsolvability was discussed in Basu (1980). 


\section{SOPHISTICATED BERTRAND OLIGOPOLY}

The game that will be considered here is one where the $n$ firms and the $m$ consumers make their decisions simultaneously. Each firm $i$ announces its price $\left(d_{i}, c_{i}\right)$ and each consumer $j$ chooses $X_{j} \in\{A, B\}$. Let us call this game "the sophisticated Bertrand Oligopoly."

An $n$-tuple of choices by the firms, $\left(\left(d_{1}, c_{1}\right), \ldots,\left(d_{n}, c_{n}\right)\right) \equiv\langle d, c\rangle$, will be called a sophisticated Bertrand equilibrium if there exists $X=$ $\left\{X_{1}, \ldots, X_{m}\right\}$, where $X_{j} \in\{A, B\}$, such that $(\langle d, c\rangle, X)$ is a Nash equilibrium of the sophisticated Bertrand oligopoly.

In conducting our analysis it is useful to distinguish between two kinds of (sophisticated Bertrand) equilibria. I shall say that an equilibrium is "symmetric" if all identical agents behave in the same way in equilibrium. Hence, in this model a "symmetric equilibrium" is a sophisticated Bertrand equilibrium in which all consumers make the same choice and all firms set the same price. A sophisticated Bertrand equilibrium that is not symmetric is called an "asymmetric equilibrium."

Recall that each firm's marginal cost of production is given by $(d(k), c(k))$. The main result of this paper is that every firm charging a price of $(d(k), 99)$ is always a sophisticated Bertrand equilibrium. And every firm charging a price of $(d(k)+1,99)$ could be a sophisticated Bertrand equilibrium, depending on the parameters of the model. No other price can occur in a symmetric equilibrium. No price below $(d(k), 99)$ and no price above $(d(k)+1,99)$ can ever be a sophisticated Bertrand equilibrium. In some markets there may exist an asymmetric equilibrium in which two prices prevail, one ending in 99 and another with a non-99 ending.

Before proving the result, let me illustrate it geometrically. Figure 1 shows the aggregate demand curve that the industry faces and each firm's marginal cost curve (as depicted by the horizontal line through point $E$ ). Because prices cannot be announced in units smaller than a cent, not all points on the demand curve, $A B$, are available but only a 'grid' of points, one cent apart. Some of these are illustrated by the round nodules marked on the line $A B$, for instance, points $E, F, G, H$, and some more unlabeled points. Let us initially consider only symmetric equilibria.

If this were standard model, with consumers always fully cognizant of the prices being charged, the oligopoly would have exactly two possible (Bertrand) equilibrium points, at $F$ and at $E$. That is, there is one Bertrand equilibrium where everybody charges the marginal cost $(d(k), c(k))$ and another Bertrand equilibrium where everybody charges one cent more than the marginal cost. In other words firms will earn zero profit or virtually zero profit. 


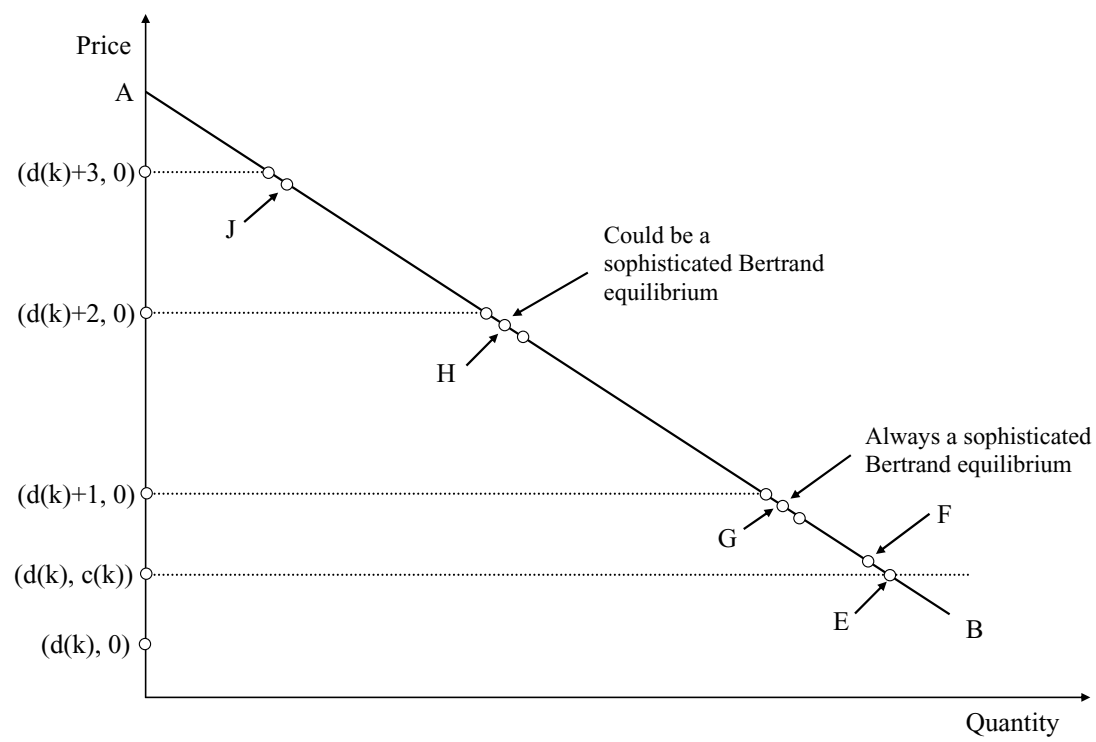

FIGURE 1. F DEPICTS A POINT ONE CENT ABOVE E. G, $H$ AND J DEPICT POINTS ONE CENT BELOW RESPECTIVELY, $(d(k)+1,0),(d(k)+2,0)$ AND $(d(k)+3,0) .(d(k), c(k))$ AND E LIE ON THE SAME HORIZONTAL LINE

In a sophisticated Bertrand oligopoly that the present paper is concerned with, $F$ and $E$ cannot be equilibrium points. Instead, point $G$ is always an equilibrium, and point $H$ may be an equilibrium.

To prove this, consider the case where all $n$ firms charge the price $(d(k), 99)$, that is, the price associated with point $G$ and the consumer chooses action $A$ (i.e., ignores the actual cent information). If a firm charges a higher price, the dollar amount charged by this firm will be higher. Hence, all consumers will notice the higher price and refuse to buy from this firm, which will therefore earn zero. If the firm charges a lower price (but one that is at least as large as $(d(k), c(k))$ no consumer will realize this. So the demand faced by this firm will be as before; and therefore its profit will be lesser. ${ }^{8}$ Because all firms charge the same price, the consumer has nothing to gain by evaluating each price

8. It may seem, at first sight, that even one firm lowering the price could have an affect on consumer demand (however small) through its effect on the average cent part of the price. But that is not so in a sophisticated Bertrand equilibrium where firms choose prices and consumers choose between being types $A$ and $B$ simultaneously. Once consumers choose $A$, they are focused on the existing average cent part. Unilateral deviations by firms have no effect on these consumers.

It is possible to alter the equilibrium definition so that consumers choosing $\mathrm{A}$, use the average cent part post deviation. In that case a unilateral deviation by a firm could affect demand (unless $n$ was assumed to be sufficiently large). 
information. In other words, she is better off choosing strategy $A$ instead of $B$. Hence, no one benefits from a unilateral deviation, and so $G$ depicts a sophisticated Bertrand equilibrium. ${ }^{9}$

Now, it will be shown that point $H$ can, under some conditions, be an equilibrium. $H$ depicts the price $(d(k)+1,99)$. Suppose all firms charge the price at $H$, that is, $(d(k)+1,99)$, and every consumer chooses action $A$. Then each firm earns a profit of $[(d(k)+1,99)-$ $(d(k), c(k))] x((d(k)+1,99)) / n$, since $(d(k), c(k)) \in[(d(k), 0),(d(k)+1,0))$. By the same logic as in the above paragraph no firm will find it worthwhile deviating to a higher price or to a lower price that is, at the same time, greater than or equal to $(d(k)+1,0)$. So now consider a firm deviating to price $(d(k), 99)$, that is, to point $G$. This firm's profit will be equal to $[(d(k), 99)-(d(k), c(k))] x((d(k), 99))$. This is because a change in the dollar part of the price is noticed by all consumers. If $(d(k), 99)=(d(k), c(k))$, then clearly such a deviation is not worthwhile. But even if $(d(k), 99)>(d(k), c(k))$, it is obvious that if $n$ is small and $(d(k), c(k))$ is close to $(d(k), 99)$, then it will not pay for any single firm to deviate to $(d(k), 99)$. And for the consumer a deviation from strategy $A$ is not worthwhile for the same reason as before.

This establishes that for certain parameters $H$ can be an equilibrium.

It will now be shown that there are no other (symmetric) equilibria in this game. Thus if $G$ and $E$ are distinct points (i.e., $c(k)<99$ ), then all firms charging the price depicted by $E$ cannot be an equilibrium. Similarly for $F$.

To prove this, first note that in no symmetric Nash equilibrium will the consumers choose action $B$. If the consumers prefer action $B$, it must be the case that there are firms $i$ and $j$ which charge different prices and manage to sell. But if the consumers choose action $B$, then they are fully cognizant of prices and so no one will buy from the firm charging a higher price. This is a contradiction, which establishes that all consumers will choose action $A$ in a symmetric Nash equilibrium.

If all consumers choose action $A$, then all firms will choose prices that end in 99. Hence, only prices like $G$ and $H$ (the first and second points, above the marginal cost where the price ends in 9) can qualify. We have already shown that $G$ is always an equilibrium and $H$ may be an equilibrium. The proof is completed by showing that no price above $H$ can be an equilibrium.

Without loss of generality, consider the next price above $H$, where the price ends in 99 . This is shown by point $J$. If all firms charge this price, each firm will earn a profit of

9. The figure in this paper is drawn for the case where $c(k)<99$. If $c(k)=99$, it is easy to see that each firm charging a price of $(d(k), 99)$ is a sophisticated Bertrand equilibrium. 


$$
\begin{aligned}
P_{1} & \equiv[(d(k)+2,99)-(d(k), c(k))] \frac{x((d(k)+2,99))}{n} \\
& =2 \frac{x((d(k)+2,99))}{n}+[(d(k), 99)-(d(k), c(k))] \frac{x((d(k)+2,99))}{n} .
\end{aligned}
$$

If one firm deviates to price $(d(k)+1,99)$, then such a firm will earn a profit of

$$
\begin{aligned}
P_{2} & \equiv[(d(k)+1,99)-(d(k), c(k))] x((d(k)+1,99)) \\
& =x((d(k)+1,99))+[(d(k), 99)-(d(k), c(k))] x((d(k)+1,99)) .
\end{aligned}
$$

Because $n \geq 2$ and $x((d(k)+2,99))<x((d(k)+1,99))$, it follows that $x((d(k)+1,99))>\frac{2 x((d(k)+2,99))}{n}$. It is therefore obvious that $P_{2}>P_{1}$. Hence, $J$ cannot be sustained as an equilibrium. By a similar proof we can establish that for no $t \geq 3$ can each firm charging $(d(k)+t, 99)$ be an equilibrium.

This completes the proof of our main result for the symmetric case.

In this oligopolistic market there could be some asymmetric (sophisticated Bertrand) equilibria as well. But these will always belong to the following class. There will exist two prices $(d(k), 99)$ and $(d(k), c(k)+1)$, or $(d(k)+1,99)$ and $(d(k)+1,0)$, and each firm will announce one of the two prices. Some consumers will choose action $B$ (I shall call them discerning consumers since they act discerningly in equilibrium.) and others will choose action $A$. This is an unlikely and nongeneric equilibrium and I present it here for reasons of completeness.

To see this, consider a case where some consumers choose to be discerning and some nondiscerning. It is first easy to see that all firms will charge prices that are identical in the dollar parts. If not, all consumers - the discerning and the nondiscerning — will ignore the firms charging a higher dollar price. It is easy to see (using the same kind of reasoning as before) that prices cannot be above $(d(k)+1,99)$. Hence, all firms will charge a price with the dollar part equal to $d(k)$ or they will all set the dollar part equal to $d(k)+1$.

Without loss of generality, let me focus on the $d(k)$-case. That is, it will be shown that there could be an equilibrium where two prices prevail: $(d(k), 99)$ and $(d(k), c(k)+1)$. Suppose there are more than two prices prevailing. In that case, there exist two firms charging prices $(d(k), a)$ and $(d(k), b)$ where $a<b<99$. Hence, the only consumers who go to the firm charging price $(d(k), b)$ will be the nondiscerning ones. In that case a firm charging $(d(k), b)$ could raise price to $(d(k), 99)$ without losing customers. This is a contradiction. 
Therefore, if there is an asymmetric equilibrium, there will exist two prices: $(d(k), 99)$ and $(d(k), c(k)+1)$. To see that there can be such an equilibrium, assume that there exists $\psi^{*} \epsilon(0,1)$ such that if a fraction $\psi^{*}$ of firms charge $(d(k), 99)$ and fraction $\left(1-\psi^{*}\right)$ charge $(d(k), c(k)+1)$, then consumers are indifferent between actions $A$ and $B$. For future discussion I shall refer to this as the "indifference axiom." If no such $\psi^{*}$ exists, that is, the indifference axiom is invalid, then the oligopoly will not have any asymmetric equilibrium. Let us consider here the interesting case where the indifference axiom holds; and let the $\psi^{*}$ referred to below be precisely these values.

It will now be shown that, if there exists a number $\phi^{*} \epsilon(0,1)$, such that if a fraction $\phi^{*}$ of consumers choose $A$ and a fraction $1-\phi^{*}$ choose $B$, then firms are indifferent between charging $(d(k), 99)$ and $(d(k), c(k)+1)$, and we do have an equilibrium in which some firms set price equal to $(d(k), 99)$ and some firms set price at $(d(k), c(k)+1)$.

To see this consider $\phi$ to be a fraction and suppose $m \phi$ consumers choose action $A$. All others choose action $B$. Using $x$ to denote $c(k)+1$, let $\bar{\pi}_{99}$ and $\bar{\pi}_{x}$ be the total profits earned by all firms charging a price of, respectively, $(d(k), 99)$ and $(d(k), x)$,

$$
\begin{aligned}
\bar{\pi}_{99} & =m \psi^{*} \phi(99-c(k)), \\
\bar{\pi}_{x} & =m\left(1-\psi^{*} \phi\right)(x-c(k)) .
\end{aligned}
$$

To understand this note that firms charging $(d(k), 99)$ will only get consumers who choose action A. There are $m \phi$ consumers who choose this action. Because these consumers choose among firms randomly, a fraction $\psi^{*}$ of these consumers go to the firms charging $(d(k), 99)$ since $\psi^{*}$ is the fraction of firms charging this price. From each consumer, such a firm earns a profit of $99-c(k)$. This explains the value of $\bar{\pi}_{99} . \bar{\pi}_{x}$ is derived in the same way by simply noting that all other consumers (i.e., $m-m \psi^{*} \phi$ of them) go to firms charging $(d(k), x)$.

Let $\pi_{99}$ and $\pi_{x}$ be the profits earned by each firm charging, respectively, a price of $(d(k), 99)$ and $(d(k), x)$. Hence,

$$
\begin{aligned}
\pi_{99} & =\frac{m \psi^{*} \phi(99-c(k))}{n \psi^{*}}=\frac{m \phi(99-c(k))}{n}, \\
\pi_{x} & =\frac{m\left(1-\psi^{*} \phi\right)(x-c(k))}{n\left(1-\psi^{*}\right)} .
\end{aligned}
$$

Let $\phi^{*} \epsilon(0,1)$ be the value of $\phi$, which makes $\pi_{99}=\pi_{x}$. That is,

$$
\pi_{99}=\frac{m \phi^{*}(99-c(k))}{n}=\frac{m\left(1-\psi^{*} \phi^{*}\right)(x-c(k))}{n\left(1-\psi^{*}\right)}=\pi_{x} .
$$


If $m \phi^{*}$ consumers choose action $A$ and $n \psi^{*}$ firms set price equal to $(d(k), 99)$ we have an equilibrium. Consumers, we already know by the indifference axiom, are indifferent between $A$ and $B$. Therefore none of them has an incentive to deviate. Observe next that $\pi_{99}$ does not depend on $\psi$ and that

$\pi_{x}(\psi) \equiv \frac{m\left(1-\psi \phi^{*}\right)(x-c(k))}{n(1-\psi)}$,

is an increasing function of $\psi$. Hence, starting with $n \psi^{*}$ firms choosing $(d(k), 99)$, if one more firm switches to $(d(k), x)$ then this firm's profit will decline, since $\pi_{99}=\pi_{x}\left(\psi^{*}\right)$ and $\pi_{99}>\pi_{x}(\psi)$, for all $\psi<\psi^{*}$. And, if a firm charging $(d(k), x)$ switches to charging $(d(k), 99)$ it will get the same profit as before and if it switches to $(d(k), c(k))$, it will earn zero. Hence, what we have is a Nash equilibrium or, equivalently, a sophisticated Bertrand equilibrium of an oligopoly.

To sum up, the model predicts that prices will generally end in nines but in some markets there will be two modal price endings, one of which will invariably be 9 . It is interesting to note that the asymmetric equilibrium in which the non-9 ending occurs would exist only if the indifference axiom holds. It is arguable that for products where people buy large amounts of some commodity or agree to a per unit price and then buy the commodity or service over a long period of time the indifference axiom is less likely to be satisfied. In such cases a small price difference translates into a large loss or gain for the buyer and hence consumers are more likely to take cognizance of the exact price. Therefore, for these kinds of goods multiple prices are less likely to occur in the same market.

\section{IMPLICATIONS AND EXTENSIONS}

The model constructed in this paper explains why we see such widespread prevalence of prices that end in 99 cents. Of course, for more valuable goods where prices do not go into cents, what this model implies is that the last nonzero digit of the price will be a 9. Thus a car could have a price of $\$ 15,690$ and a holiday in the Bahamas may command a price of $\$ 899 .{ }^{10}$ Conversely, for goods that are very cheap,

10. There is indeed an open question about how far to the right the nines go. Why is the car not priced at $\$ 15,699.99$ and why does the Bahamas vacation not cost $\$ 899.99$ ? The formal result that we have discussed here is that if we think of every number as having an endless sequence of digits after the decimal point, then the last nonzero digit will tend to be 9 . What we do not have is a theory of where the nines stop and the zeros take over. At an informal level it is arguable that a car maker who sets a price at $\$ 15,699.99$ will frighten away customers by appearing extortionate. ("Would she not also have saved money by compromising on the quality of the break?" the customer may wonder.) But this is a separate problem that deserves to be investigated separately. 
for instance, less than a dollar, a similar argument can be used to show that only the last digit will be 9, for example, a candy for 49 cents.

Unlike in the model of monopoly discussed in Basu (1997), we find that firms benefit from this phenomenon of pricing in the nines. This enables (sophisticated) Bertrand oligopolists to sustain a price above the marginal cost (and even above the prices that could prevail in the standard Bertrand oligopoly model with an exogenously fixed smallest unit of change). Also, unlike in a monopoly, some non-9 endings are now possible in equilibrium.

The non-9 endings are, however, nongeneric outcomes in the model. Some natural extensions of the above model can, however, explain why 9 endings, though pervasive, are not as widespread as this model suggests. Note that in this model the consumer forms an expectation about the cent part of the price on the basis of the average cent part of all prices for the same good. An alternative model could go as follows. Suppose there are $t$ products and for each product there are $n$ firms producing it. Assume that consumers ignore looking at the cent part of the price when buying a good, just as in the above model, but assume the cent part to be whatever is the average cent part for all goods in all markets.

If this is how people form their expectations, then we can get some results that do not occur in the above model. Suppose that for product $i$ 's market all $n$ firms choose the cent part of the price to be $c_{i}$. And suppose for some $i, j, c_{i} \neq c_{j}$. This could lead all consumers to be of type $B$. That being so we could have an equilibrium in which $c_{i} \neq c_{j}$ persists. Hence, non-9 price endings could be prevalent. However, in the same model we could have another equilibrium where $c_{i}=99$, for all $i$, and all consumers choose to be of type A. Hence, clearly we can have multiple equilibria in such a model.

Because as yet we do not have enough empirical data to know exactly how consumers form expectations about the cent parts or the last digits of a price, it is important to take both the above kinds of assumptions seriously.

Another natural way to extend the model is to suppose that, if a person is planning a very large purchase, he takes cognizance of the exact per unit price of the product since even a tiny difference in per unit price could make a big difference to his cost. While I have not modeled this formally here, it is reasonable to expect that in such situations the indifference axiom discussed above will be violated and so we will invariably see only one price for each good. If we go a step further and introduce the idea of "cautious behavior" on the part of consumers, which is defined behavior that takes into account the possibility of "trembles" in prices whether or not there exists any actual price variability in the market, then it is likely that the dominance of 
the 9 endings will break down. For goods, where the consumer places large orders (i.e., several multiples of the unit) on the basis of a per unit price, there will be a unique price but there will be no special reason for this to have a 9 ending. Therefore, for goods like cement, house paint, phone calls, and long-term lawn-mowing contracts we will be less likely to see 9-price endings. By the same kind of reasoning we would expect to see a wider use of prices ending in 9 in the retail market, where small quantities of goods are purchased, or in the market for perishable goods, as opposed to, for instance, the wholesale market.

In general, this paper suggests that, instead of assuming consumer irrationality and consumer psychological delusion, if we simply recognized that consumers have limited time for decisionmaking and limited brain capacity and they act rationally subject to these limitations, then we can get results that elude the standard literature on industrial pricing and mimic some of the results that behavioral economics derives only by assuming consumer irrationality.

This is not to suggest that consumers are never irrational but simply that we must not be too hasty in jumping to the conclusion of irrationality either. Many interesting, nonstandard results and testable propositions can be derived from models that deviate from the textbook neo-classical model, while retaining the precept of rationality.

\section{REFERENCES}

Anderson, E. and D. Simester, 2003, “Effects of \$9 Price Endings on Retail Sales: Evidence from Field Experiments," Quantitative Marketing and Economics, 1, 93-110.

- and —- 2003a, "Mind Your Pricing Cues," Harvard Business Review, 81, 96-103.

Bader, L. and J.D. Weinland, 1932, “Do Odd Prices Earn Money?” Journal of Retailing, 8, 102-104.

Basu, K., 1980, Revealed Preference of Government, Cambridge, UK: Cambridge University Press.

_ 1988, "Strategic Irrationality in Extensive-form Games," Mathematical Social Science, $15,247-260$.

- 1992, Lectures in Industrial Organization Theory, Oxford, UK: Blackwell Publishers.

_ 1997, “Why are so many Goods Priced to End in Nine? And Why This Practice Hurts the Producers?" Economics Letters, 53, 41-44.

Evans, J.R. and B. Berman, 1997, Marketing, Englewood Cliffs, NJ: Prentice Hall.

Fazio, R.H., J.-M. Chen, E.C. McDonel, and S.J. Sherman, 1982, “Attitude Accessibility, Attitude-Behavior Consistency, and the Strength of the Object-Evaluation Association," Journal of Experimental Social Psychology, 18, 339-357.

Friberg, R. and T.Y. Matha, 2003, "Does a Common Currency Lead to (more) Price Equalization? The Role of Psychological Pricing Points," Mimeo: Stockholm School of Economics, forthcoming Economic Letters.

Gabor, A. and C. Granger, 1964, "Price Sensitivity of the Consumer," Journal of Advertising Research, 4, 40-44.

Gigerenzer, G. and D.G. Goldstein, 1996, "Reasoning the Fast and Frugal Way: Models of Bounded Rationality," Psychological Review, 103, 650-669. 
— Bounded Rationality, Cambridge, MA: The MIT Press.

Ginsberg, E., 1936, “Customary Prices,” American Economic Review, 26, 296.

Goldstein, D.G. and G. Gigerenzer, 1999, "Betting on One Good Reason: The Take the Best Heuristic," in G. Gigerenzer, P.M. Todd, and the ABC Research Group, eds., Simple Heuristics that Make Us Smart, New York: Oxford University Press.

Inman, J.J., L. McAlister, and W.D. Hoyer, 1990, “Promotional Signal: Proxy for a Price Cut," Journal of Consumer Research, 17.

Kahneman, D. and A. Tversky, 1979, "Prospect Theory: An Analysis of Decision Under Risk," Econometrica, 47, 263-291.

Lui, Q. and K. Serfes, 2004, "Quality of Information and Price Discrimination," Journal of Economics and Management Science, 13, 671-702.

Nagle, T.T. and R.K. Holden, 1995, The Strategy and Tactics of Pricing, 2nd edition, Englewood Cliffs, NJ: Prentice Hall.

Ruffle, B.J. and Z. Shtudiner, 2003, "99: Are Retailers Best Responding to Rational Consumers? Experimental Evidence," Mimeo: Ben-Gurion University, forthcoming Managerial and Decision Economics.

Schindler, R.M. and T.M. Kibarian, 1996, "Increased Consumer Sales through Use of 99 Ending Price," Journal of Retailing, 72, 187-199.

— Implications for Nine-Ending Effects," Journal of Customer Research, 24, 192-201.

Shy, O., 2000, "Why 99 Cents?" Mimeo: University of Haiffa.

Stiving, M., 2000, “Price-Endings When Prices Signal Quality," Management Science, 46, $1617-1629$.

— Journal of Customer Research, 24, 57-67.

Thaler, R., 1985, "Mental Accounting and Consumer Choice," Management Science, 4, 199214.

Todd, P.M., 2001, "Fast and Frugal Hewistics for Environmentally Bounded Minds," in G. Gigerenzer and R. Selten, eds., Bounded Rationality, Cambridge, MA: The MIT Press.

_ Psychology, 24, 143-165.

Wilkie, W., 1990, Consumer Behavior, New York: Wiley and Sons. 